\title{
Development status and Prospect of directional hydraulic fracturing technology for coal mine roof
}

\author{
LI Liangwei $1,2, *$ \\ ${ }^{1}$ Chongqing Research Institute, China Coal Technology and Engineering Group, Chongqing 400037, China \\ ${ }^{2}$ State Key Laboratory of The Gas Disaster Detecting, Preventing and Emergency Controlling, Chongqing 400037, China
}

\begin{abstract}
Aiming at the harm and control methods of thick and hard roof in coal mine, the paper firstly analyzes the advanced control methods of thick and hard roof, such as directional shaped charge blasting roof control technology, hydraulic fracturing roof control technology, abrasive water jet directional cutting roof technology, large-scale special roof cutting machine, etc Control hole fracturing, transverse slotting fracturing and longitudinal slotting fracturing are compared and analyzed; finally, the shortcomings of current research are analyzed. According to the current research results, the analysis shows that: the method of controlling roof by blasting in the future will be limited, while the method of hydraulic fracturing, especially directional hydraulic fracturing, has obvious advantages; the longitudinal slotting fracturing has the best control over fractures in the directional hydraulic fracturing technology; the guiding mechanism and fracture extension mechanism of longitudinal slotting hydraulic fracturing in thick and hard roof need to be further studied; lack of field application research and corresponding equipment development, lack of field effect evaluation method after longitudinal slotting fracturing.
\end{abstract}

\section{Preface}

In recent years, the number of roof accidents and the number of single death caused by rock burst or rock burst are on the rise [1]. According to the survey results, the thick and hard roof coal mines in western mining areas such as Xinjiang, Shaanxi, Shanxi and other regions account for more than $35 \%$ of the coal mines in the whole region. Due to the large hanging area of the roof and the factors of large mining height, the periodic weighting step distance is too large, the periodic weighting impact is strong, the roadway deformation, support damage and other hazards, which will indirectly bring gas, coal dust explosion and other secondary disasters. The key factor of rock burst in deep mines such as Shandong, Heilongjiang and other areas is also the rock with thick and hard roof. The elastic energy accumulated in the thick and hard roof layer suddenly releases, which can lead to rock burst without warning.

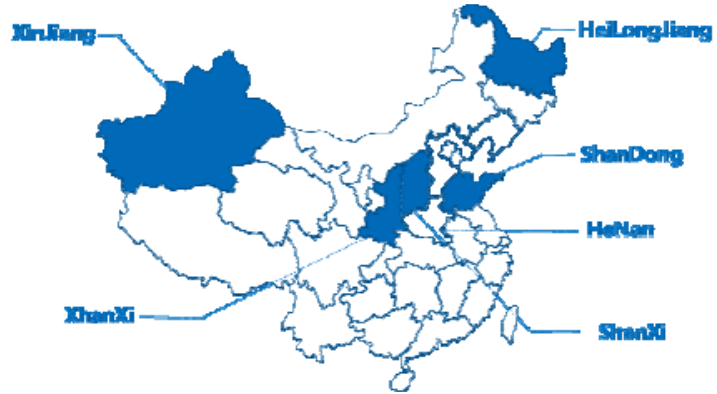

Fig. 1. Distribution of thick and hard roof mines and deep mines in China
Rock burst is one of the most serious ways of mine pressure manifestation. In essence, it is the release of elastic properties of coal and rock mass caused by in-situ stress concentration. Most of the rock burst mines also have thick hard roof factors. Therefore, the essence of solving rock burst is still consistent with that of Western Mining area, and it is still to solve the problem of roof cutting of thick and hard roof to achieve the purpose of stress transfer [2]. The most important mining factors are mining mode and roof treatment mode. Under the influence of mining, along the advancing direction of mining face, the stress of coal pillars on both sides of mining space changes with the distance and time from the working face. Under the influence of abutment pressure, with the influence of mining, the load of coal pillar for roadway protection will increase rapidly, the deformation of outer roadway will become larger, and the roadway spalling and floor heave will occur [3].
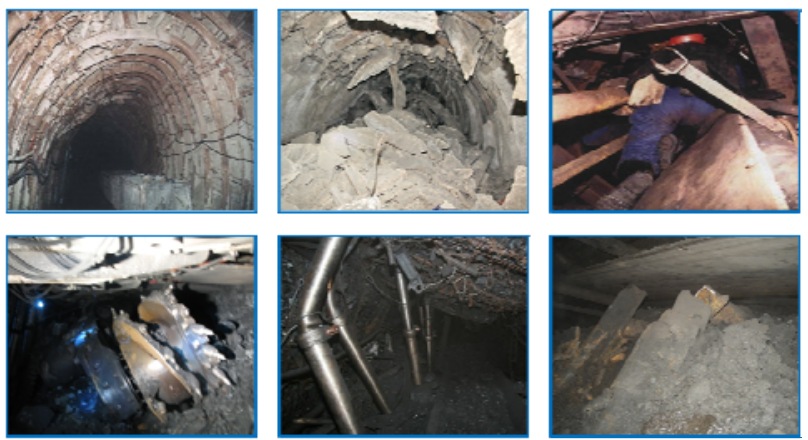

Fig. 2. Hazard of rock burst and thick hard roof

\footnotetext{
*Corresponding author: sccqxu1@,foxmail.com
} 
In order to reduce the late deformation degree of roadway, reduce the roadway repair and reinforcement support strength, or to avoid the occurrence of rock burst disaster, it is necessary to solve the fundamental problem from the source. It is necessary to take measures to cut off the roof and relieve the pressure on the thick hard roof layer to reduce the length and surface area of the hanging roof of the working face, so as to weaken the high stress stored in the overlying strata of the working face and relieve the stability of the roadway caused by mining It can reduce the difficulty of roadway maintenance and avoid mine pressure disaster [4]. In this paper, the control technology of thick and hard roof and directional hydraulic fracturing technology in China are summarized, the shortcomings of current directional hydraulic fracturing technology are found, and the prospect of longitudinal slotting hydraulic fracturing technology is proposed.

\section{Research status of thick and hard roof control technology}

Roof control technology of directional shaped charge blasting method. How man Chao [5] and others based on directional blasting to achieve automatic roadway forming technology of roof cutting and pressure relief, and analyzed the evolution process of roof structure of roadway along goaf, obtained the transmission mechanism of stress and displacement of surrounding rock of roadway formed by roof cutting in thick coal seam, formed the control idea of actively constructing surrounding rock stable structure of "basic roof upper rock layer goaf broken swelling gangue roadway roof cutting short arm beam" The roof is controlled by the constant resistance and large deformation anchor cable, and the side part is controlled by the wave type multi resistance anchor rod, which forms the coping roof structure and forms the surrounding rock collaborative control system of roof cutting roadway along goaf in rapid mining of thick coal seam.

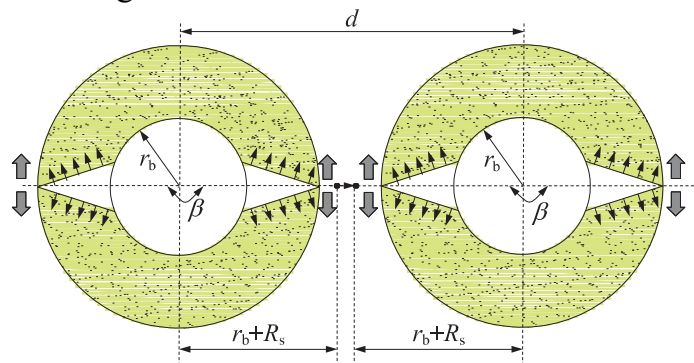

Fig. 3. Directional shaped charge blasting

Hydraulic fracturing roof control technology. Huang Bingxiang [6] systematically studied the theory of hydraulic fracturing weakening of coal and rock mass by means of experimental research, theoretical analysis, numerical simulation and field test. Duhailong [7] adopts hydraulic fracturing to solve the hidden danger of upper end roof, and the maximum hanging roof area is less than $10 \mathrm{~m}^{2}$. At the same time, the maximum working resistance of the head support can be reduced by $27.6 \%$ and the average periodic weighting step distance is reduced by $24.8 \%$. Kang Hongpu [8] has developed a lateral slotting bit, which uses the slotting as the fracturing guidance, and has carried out downhole field fracturing experiments, and has achieved certain results, and the hydraulic fractures expand well along the horizontal direction.

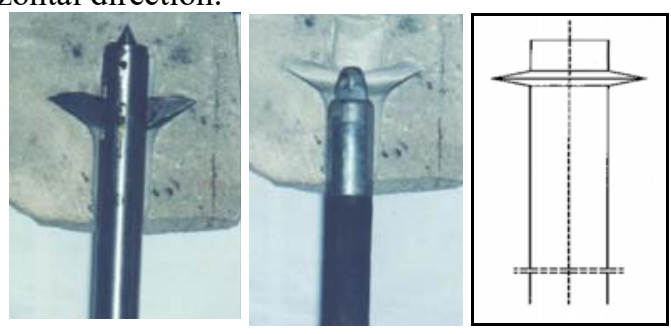

Fig. 4. Transverse grooving bit and groove shape

Hydraulic fracturing roof control technology. $\mathrm{Lu}$ Yiyu et al. [9] developed a "liquid directional seam cutting machine" on the basis of continuous abrasive water jet system, using the front mixed abrasive water jet to complete the underground test of cutting roof, providing key support for the test site of self formed roadway without coal pillar (N00 construction method). It can realize the directional continuous cutting of roof strata in the four holes, cut through the roof rock vertically and through the four holes horizontally, form a smooth section of the roof above the roadway side of the goaf, guide the roof to collapse along this section, and cooperate with the constant resistance and large deformation anchor rod to hold the roof of the retained roadway, and finally realize the gob side entry retaining of "pulling and laying down".

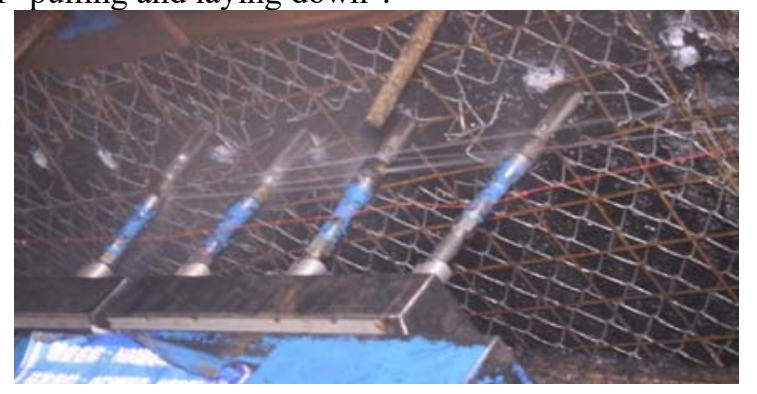

Fig. 5. Liquid roof cutting machine

Large special roof cutting machine. In November 2019, the klj7 mining intelligent chain arm saw roof cutting machine, which was first developed by Tongmei coal group, achieved successful test, which created a precedent for rapid roof cutting and slotting and pressure relief of mechanical equipment underground, and promoted the transformation of top cutting technology of coal pillar free working face from "manual blasting top cutting" to "mechanical precise roof cutting" [10].

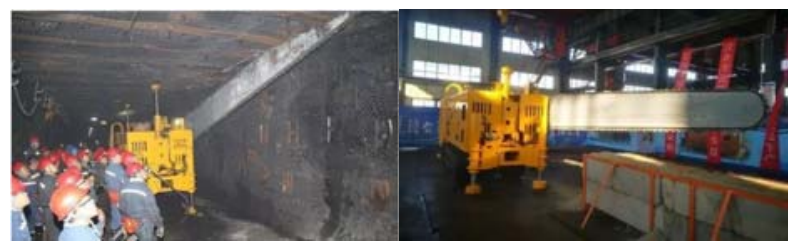

Fig. 6. Chain saw roof cutting machine 


\section{Research status of directional hydraulic fracturing}

At present, more and more blasting and hydraulic fracturing methods are used to cut the top and release pressure. Because the control of initiating explosive device is more and more strict, the safety of top cutting and pressure relief of blasting method is lower and more restricted, and the advantages of hydraulic fracturing are more and more prominent. However, in order to control the roof, it is necessary to control the cracking and extension of fracturing fractures. Therefore, the directional hydraulic fracturing method is proposed. The main methods of directional fracturing are directional perforation fracturing, control hole fracturing, transverse slotting fracturing and longitudinal slotting fracturing.

Liu He [11] pointed out that in the stimulation measures of oil and gas development, directional perforation and hydraulic fracturing technology can be used to prefabricate directional guide holes by means of perforating charges and sandblasting jet perforations. So as to control the starting direction of hydraulic fracturing. Wang Zhijun [12] and others analyzed the commonly used hydraulic fracturing fracture control methods by using numerical calculation and mechanical analysis method, as shown in Fig. 7. The guiding and controlling methods are divided into axial, annular and control hole.
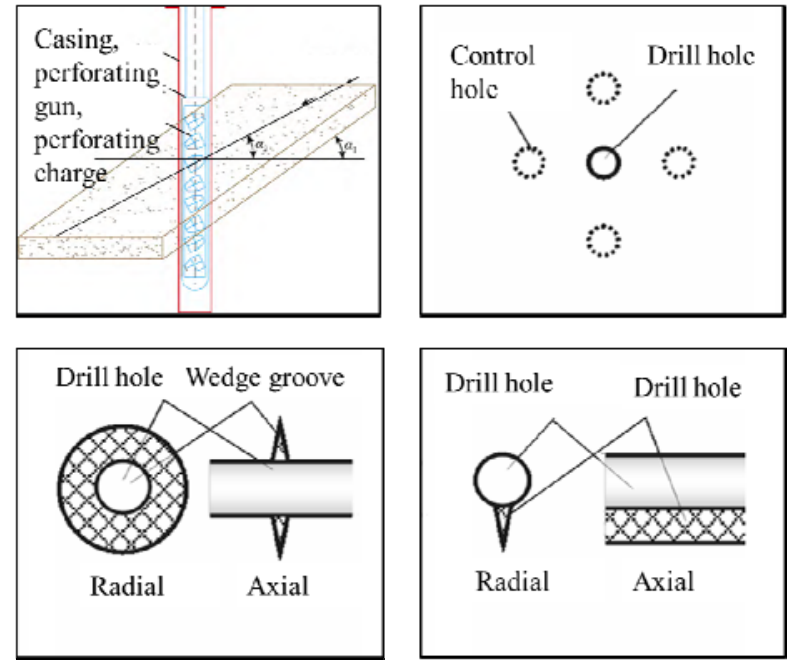

Fig. 7. Classification of fracture control methods

\subsection{Directional perforation hydraulic fracturing technology}

Hubbert et al. [13] revealed that fracture initiation is independent of rock elastic parameters, borehole size and vertical stress, but related to in-situ stress conditions and rock properties. Behrmann et al. [14] determined that fracture cracking and propagation characteristics are mainly affected by in-situ stress, pump flow and perforation azimuth angle through true triaxial hydraulic fracturing test. Gong Diguang [15] and others have revealed the influence law of flow change on fracture morphology. With the increase of pump injection flow rate, the length and width of fracture increase obviously.

\subsection{Directional pilot hole hydraulic fracturing technology}

Li Quangui [16] and others designed different directional hole parameters and verified the auxiliary directional effect, which is beneficial to control the crack propagation. Chen Xuexi [17] et al. made a comparative study on the hole arrangement modes of directional holes and non directional holes. The directional holes were arranged in the middle of the two fracturing holes. The results show that the directional holes have good guiding and pressure relief effects.

\subsection{Hydraulic fracturing technology of transverse cutting groove}

Huang Bingxiang et al. [18] used the true triaxial high stress loading test system developed by ourselves to test the specimen according to in-situ stress conditions. When the intermediate principal stress is less than the minimum principal stress, the fracture is more likely to expand along the direction of the maximum principal stress. Wang Lei et al. [19] simulated natural fractures by processing the time of prefabricated transverse fractures, and obvious through fractures were observed in the specimens after fracturing. Feng Yanjun [20-22] used numerical simulation software to analyze and show that fracture cracking and propagation are greatly affected by in-situ stress conditions. The experimental results show that the propagation radius can reach $20 \mathrm{~m}$ after transverse slotting fracturing.

\subsection{Hydraulic fracturing technology of longitudinal slotting}

By establishing a large-scale numerical simulation model, Lin Jian [23] and others carried out research on longitudinal slotting hydraulic fracturing under the joint action of the maximum horizontal principal stress, the minimum horizontal principal stress and the vertical stress by using ABAQUS software. Through the hydraulic fracturing experiment, the results show that the longitudinal slotting has an obvious guiding effect on the longitudinal fracture expansion.

\section{Shortcomings of directional hydraulic fracturing research and its future development direction}

At present, a large number of directional fracturing researches focus on perforating fracturing, directional hole fracturing and transverse slotting fracturing, rarely involving longitudinal slotting fracturing, especially a small amount of laboratory research, lack of in-depth research on the vertical guiding mechanism and fracture extension mechanism of thick and hard roof, lack of field application research and corresponding equipment development, and even less the effect evaluation method after longitudinal fracturing. For the more advanced and widely used in the field, hydraulic fracturing is carried out by using the horizontal grooving bit, which is opened 
and rotated at the fixed position. The following problems still exist in this way of directional fracturing technology, such as: the theoretical research on fracture propagation and slot guiding effect is still not deep enough; multiple fracturing technology in a small range in a single hole will lead the fracture slot to the pressed hole in a short distance, and will not form a new fracture in a long distance; the use of bypass sealing in fracturing will lead to poor sealing effect, and manual pressure supplement is dangerous and cumbersome; slotting bit and drilling machine are added It is difficult to recover the slotting bit, and the most important thing is that the longitudinal guiding groove cannot be formed. There is no evaluation method for the effect after fracturing. The method of observing the image of hole wall after fracturing and judging whether it collapses after mining face advancing is a passive and lagging method.

The above problems, especially the lateral cutting and shallow fracture depth, directly lead to the failure to accurately guide the fracture propagation and control the azimuth accurately. At present, there is an urgent need for in-depth research on the effect of fracture guide and in-situ stress, the influence of fracture depth on fracture propagation principle of hydraulic fracturing, and the research and development of new equipment for slotted cutting and hydraulic fracturing integrated cutting top.

\section{Conclusion}

(1) Roof accidents and accidents dominated by roof are the most serious accidents in recent years, and thick hard roof is the key factor leading to rock burst and its leading disasters.

(2) At present, the more advanced thick and hard roof control methods include directional shaped charge blasting roof control technology, hydraulic fracturing roof control technology, abrasive water jet directional cutting roof technology, large special roof cutting machine. The blasting method will be limited in the future, and the advantages of hydraulic fracturing will be highlighted.

(3) The main methods of directional hydraulic fracturing include directional perforating fracturing, control hole fracturing, transverse slotting fracturing and longitudinal slotting fracturing, among which the longitudinal slotting fracturing has the best fracture control.

(4) The guiding mechanism and fracture extension mechanism of longitudinal slotting hydraulic fracturing in thick and hard roof need to be further studied. There is a lack of field application research and corresponding equipment development, as well as the effect evaluation method after longitudinal fracturing.

\section{Acknowledgments}

This paper was partially supported by "Thirteen FiveYear" National Major Special Projects (2016ZX05045004002, 2016ZX05067004001) and major scientific and technological innovation projects in Shandong Province(2019SDZY02). The authors also gratefully acknowledge the helpful comments and suggestions of the reviewers, which have improved the document.

\section{References}

1. R.L. Zhong, W.W. Ww, F.Y. Liu. Coal Technology 39, 205-207 (2020)

2. Z.Y. Sun, Y.J. Feng, X.P. Guo. China Mining Magazine 23, 108-110 (2014)

3. J. Yang, L.K. Qiao, K.F. Zhou. China Mining Magazine 26, 112-116 (2017)

4. X.S. Guo, B.G. Cui, H.K. Dang. China Mining Magazine 25, 105-107 (2016)

5. M.C. He, Y.B. Gao, J. Yang. Rock and Soil Mechanics 39, 254-264 (2018)

6. B.X. Huang. China Mining University (2009)

7. H.L. Du. Coal Engineering 49,86-89,92 (2017)

8. Y.J. Feng, H.P. Kang. Chinese Journal of Rock Mechanics and Engineering 31,1148-1155 (2012)

9. Y.Y. Lu, L.W. L, J.R. Tang. Journal of Chongqing University 41, 111-120 (2018)

10. J. B. Journal of Tiefa science 1, 127-127 (2019)

11. H. Liu, F. Wang, Y.C. Wang. Petroleum Exploration and Development 41, 731-737 (2014)

12. Z.J. Wang, C.J. Lian, G.Y. Wang. Chinese Journal of Geotechnical Engineering 35, 320-324 (2013)

13. M.K. Hubbert, D.G. Willis. Transactions of Society of Petroleum Engineers of AIME 210, 153-168 (1957)

14. L.A. Behrmann. JPT 91, 608-615 (1991)

15. D.G. Gong, Z.Q. Qu, J.X. Li. Rock and Soil Mechanics 37, 1512-1520 (2016)

16. Q.G. Li, C. Zhai, B.Q. Lin. Journal of Xi'an University of Science and Technology 31, 735-739 (2011)

17. X.X. C, Y. Xu, W.G. Jin. Journal of Liaoning Technical University 2016, 124-128 (2016)

18. B.X. Huang. Journal of China Coal Society 2010, 1765-1766 (2010)

19. L. Wang, C.H. Yang, Z.K. Hou. Rock and Soil Mechanics 2016, 88-94 (2016)

20. Y.J. Feng. General Research Institute of Coal Science (2013)

21. Y.J. Feng, H.P. Kang. Journal of China Coal Society, 38, 226-232 (2013)

22. Y.J. Feng, H.P. Kang. Chinese Journal of Rock Mechanics and Engineering 31, 1148-1155 (2012)

23. J. Lin. Acceptance materials for science and technology projects of China Coal Science and Industry Group Co., Ltd 2013, MS010 (2015) 